\title{
Lung function decline in asthma patients with elevated bronchial CD8, CD4 and CD3 cells
}

Irene den Otter ${ }^{1}$, Luuk N.A. Willems ${ }^{1}$, Annemarie van Schadewijk ${ }^{1}$, Simone van Wijngaarden ${ }^{1}$, Kirsten Janssen ${ }^{1}$, Ronald C. de Jeu ${ }^{1}$, Jacob K. Sont ${ }^{2}$, Peter J. Sterk ${ }^{1,3}$ and Pieter S. Hiemstra ${ }^{1}$

Affiliations: 'Dept of Pulmonology, Leiden University Medical Center, Leiden, The Netherlands. ${ }^{2}$ Dept of Medical Decision Making, Leiden University Medical Center, Leiden, The Netherlands. ${ }^{3}$ Dept of Respiratory Medicine, Academic Medical Center, University of Amsterdam, Amsterdam, The Netherlands.

Correspondence: Irene den Otter, Dept of Pulmonology, C2-P, Leiden University Medical Center, Albinusdreef 2 , 2333 ZA Leiden, The Netherlands. E-mail: I.den_Otteralumc.nl

ABSTRACT Which inflammatory markers in the bronchial mucosa of asthma patients are associated with decline of lung function during 14 years of prospective follow-up?

To address this question, 19 mild-to-moderate, atopic asthmatic patients underwent spirometry and bronchoscopy at baseline and after 14 years of follow-up $(\mathrm{t}=14)$. Baseline bronchial biopsies were analysed for reticular layer thickness, eosinophil cationic protein (EG2), mast cell tryptase (AA1), CD3, CD4 and CD8. Follow-up biopsies were stained for EG2, AA1, neutrophil elastase, CD3, CD4, CD8, CD20, granzyme B, CD68, DC-SIGN, Ki67 and mucins.

Decline in forced expiratory volume in $1 \mathrm{~s}\left(\mathrm{FEV}_{1}\right) \%$ predicted was highest in patients with high CD8 ( $\mathrm{p}=0.01$, both pre- and post-bronchodilator) or high $\mathrm{CD} 4$ counts at baseline $(\mathrm{p}=0.04$ pre-bronchodilator, $\mathrm{p}=0.03$ post-bronchodilator). Patients with high $\mathrm{CD} 8, \mathrm{CD} 3$ or granzyme $\mathrm{B}$ counts at $\mathrm{t}=14$ also exhibited faster decline in FEV1 ( $\mathrm{p}=0.00 \mathrm{CD} 8$ pre-bronchodilator, $\mathrm{p}=0.04 \mathrm{CD} 8$ post-bronchodilator, $\mathrm{p}=0.01$ granzyme $\mathrm{B}$ pre-bronchodilator, and $\mathrm{p}<0.01 \mathrm{CD} 3$ pre-bronchodilator).

Long-term lung function decline in asthma is associated with elevation of bronchial CD8 and CD4 at baseline, and CD8, CD3 and granzyme B at follow-up. This suggests that high-risk groups can be identified on the basis of inflammatory phenotypes.

@ERSpublications

Mild-to-moderate asthma subgroups with steeper lung function decline can be identified based on inflammatory markers http://ow.ly/4mJe89

Editorial comment in: Eur Respir J 2016; 48: 287-290.

This article has supplementary material available from erj.ersjournals.com

Received: Sept 112015 | Accepted after revision: April 042016 | First published online: May 262016

Support statement: This study was supported by a grant from the Netherlands Asthma Foundation (grant number: 3.2.03.50). Funding information for this article has been deposited with FundRef.

Conflict of interest: Disclosures can be found alongside this article at erj.ersjournals.com

Copyright @ERS 2016 


\section{Introduction}

Asthma is a chronic inflammatory disease of the airways, ranging from mild to severe, with mostly reversible airway obstruction. In asthma patients it has been shown that the decline in lung function is steeper over time when compared with healthy subjects [1], but variation in this decline amongst asthma patients is substantial $[2,3]$. Clinical subgroups can be observed with different degrees of lung function decline [1].

Besides inflammation of the airways, structural changes to the airways can be observed in asthma, including thickening of the subepithelial reticular layer, changes in the extracellular matrix, thickening of the smooth muscle layer and increased numbers of goblet cells in the surface epithelium [4]. This so-called airway remodelling might result in a decline in lung function over time in some, but not in all, asthma patients.

Understanding the basis of lung function decline in asthma is clinically relevant, since in a subgroup of asthma patients lung function decline can progress into persistent airflow limitation [5]. Furthermore, LANGE et al. [6] showed that reduced lung function was associated with increased mortality in patients with asthma. Identification and characterisation of phenotypic subgroups of asthma holds promise for asthma management [7]. Studies on the presence of eosinophils and neutrophils led to characterisation of subgroups that differed in their severity of disease (exacerbations) and response to therapy $[8,9]$. However, longitudinal studies that characterise such phenotypes based on decline of lung function have not been performed.

Starting in 1993, our group established a cohort of well-characterised, mild-to-moderate asthma patients [10]. We showed that after 7.5 years of follow-up the number of CD8 cells in bronchial biopsies at baseline was predictive for the subsequent decline in (post-bronchodilator) forced expiratory volume in $1 \mathrm{~s}$ (FEV1) [11], indicating that inflammation is associated with lung function decline during these first years of follow-up. In the present study we hypothesised that inflammatory subtypes in bronchial biopsies taken at baseline $(\mathrm{t}=0)$ are predictive of subsequent long-term lung function decline after 14 years of follow-up $(\mathrm{t}=14)$, and that inflammatory patterns at 14 years follow-up are also associated with the (previous) decline in lung function.

Therefore, the aim of our study was to characterise inflammation in bronchial biopsies by staining for markers of both innate (eosinophil cationic protein (EG2), mast cell tryptase (AA1), neutrophil elastase, CD68 and DC-SIGN) and adaptive immunity (CD3, CD4, CD8 and granzyme B), as well as markers for remodelling (mucins) and local proliferation (Ki67). We examined the relationship between these inflammatory and remodelling markers and decline in lung function during 14 years of prospective follow-up. Such characterisation of asthma phenotypes and identification of high-risk groups aims to facilitate future personalised management strategies.

\section{Methods}

Subjects

The cohort of the Asthma Management Protocol University Leiden (AMPUL) study originally consisted of 75 atopic patients with mild-to-moderate persistent asthma [10]. 45 patients underwent a successful bronchoscopy at baseline $(\mathrm{t}=0)$ and 32 patients had a clinical assessment at $\mathrm{t}=7.5$ years. Of these, 19 patients were included in the current study ( $\mathrm{t}=14$ years) (figure 1). The short-term follow-up of these patients has been reported previously $[10,11]$. The long-term follow-up of the patients is described in detail in the supplementary material. A flow chart of patient numbers during the 14 year follow-up study is given in figure 1. This follow-up study was approved by the Medical Ethics Committee of the Leiden University Medical Center (Leiden, The Netherlands), and all participants gave written informed consent.

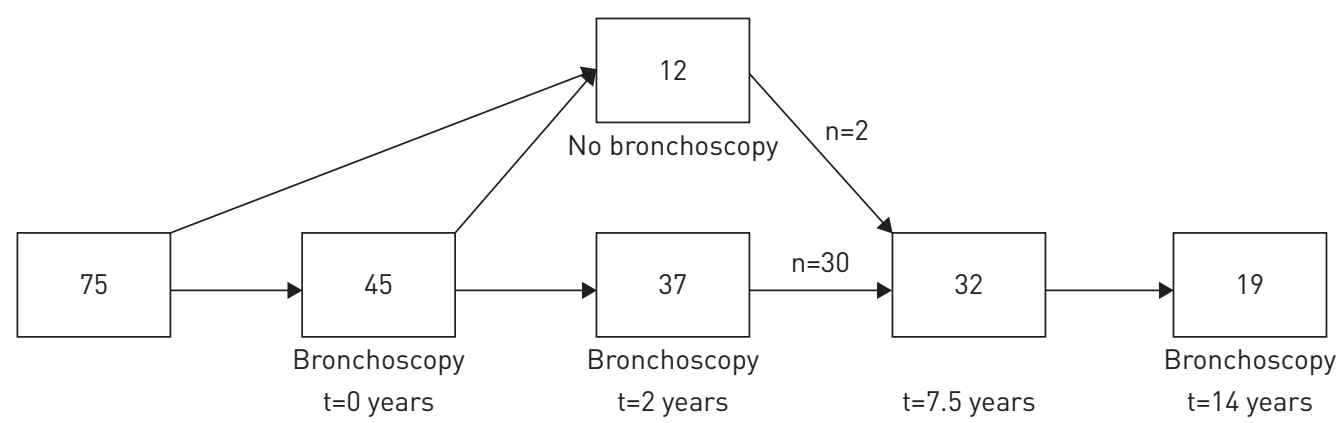

FIGURE 1 Flow chart of patient recruitment during the 14 year follow-up of the Asthma Management Protocol University Leiden cohort. 


\section{Design}

This was a prospective, observational study covering 14 years of follow-up. Pre- and post-bronchodilator FEV1 and provocative concentration causing a 20\% fall in FEV1 (PC20) were measured and bronchoscopies were performed at baseline and $t=14$ years. Details on spirometry and bronchoscopy are given in the supplementary material.

\section{Immunohistochemistry and analysis of staining}

At baseline, bronchial biopsies were analysed for reticular layer thickness, EG2, AA1, CD3, CD4 and CD8. Detailed biopsy methods have been published previously [10]. At $\mathrm{t}=14$ years, EG2, AA1, neutrophil elastase, CD3, CD4, CD8, CD68, CD20, DC-SIGN, granzyme B and Ki67 were analysed in the bronchial biopsies. Antibodies and antigen retrieval methods used are shown in table S1. For further details, see the supplementary material.

Total biopsy images were taken of all sections stained. The length of the basement membrane of both intact and damaged epithelium was determined. Ki67 was analysed in intact epithelium and was expressed as the number of $\mathrm{Ki}^{+} 7^{+}$cells per millimetre of basement membrane. Mucin expression was analysed using Periodic acid-Schiff/Alcian Blue (PAS/AB) staining in intact epithelium, and was expressed as the percentage $\mathrm{PAS} / \mathrm{AB}^{+}$area. A detailed description is provided in the supplementary material.

The number of positive stained cells for EG2, AA1, neutrophil elastase, CD3, CD4, CD8, CD68, CD20, DC-SIGN and Ki67 were counted and data were expressed as the number of positive cells per $0.1 \mathrm{~mm}^{2}$ lamina propria. Granzyme B staining was analysed semi-quantitatively, and was expressed as the fraction of biopsies that contained granzyme $\mathrm{B}^{+}$-cells (for details see the supplementary material).

\section{Statistical analysis}

Declines in pre- and post-bronchodilator $\mathrm{FEV}_{1}$ were determined between $\mathrm{t}=0$ and $\mathrm{t}=14$ years and the mean (declines in) pre- and post-bronchodilator $\mathrm{FEV} 1$ were compared. $\mathrm{EG}_{2}^{+}{ }_{-}, \mathrm{AA}^{+}{ }_{-}, \mathrm{CD}^{+}{ }_{-}, \mathrm{CD}_{4}^{+}$-, $\mathrm{CD}^{+}{ }_{-}$, neutrophil elastase ${ }_{-}, \mathrm{CD}^{+} 8^{+}, \mathrm{CD}_{2} 0^{+}, \mathrm{DC}_{-} \mathrm{SIGN}^{+}-, \mathrm{Ki}_{6} 7_{-}^{+}$and granzyme $\mathrm{B}^{+}$-cell counts, $\mathrm{PAS} / \mathrm{AB}^{+}$area and reticular layer thickness were dichotomised on the basis of median values of the staining: less than the median was defined as "low" and greater than or equal to the median as "high". Decline in pre- and post-bronchodilator $\mathrm{FEV}_{1} \%$ predicted was compared between subjects with low and subjects with high inflammatory (cell) counts using the nonparametric Mann-Whitney U-test, since data were not normally distributed and the group size was small. To further explore the associations, linear correlations between these markers and decline of $\mathrm{FEV}_{1} \%$ predicted were analysed by nonparametric Spearman's correlation analysis. Cross-sectional associations between the T-cell markers CD3, CD4 and $\mathrm{CD} 8$ and $\mathrm{FEV}_{1} \%$ predicted at $\mathrm{t}=14$ years were analysed by nonparametric analysis. Moreover, associations between $\mathrm{CD}^{+}-, \mathrm{CD}^{+}$- and $\mathrm{CD}^{+}$-cell counts at baseline and at $\mathrm{t}=14$ years were analysed.

\section{Results}

\section{Patient characteristics}

Among the 32 patients who participated at 7.5 years of follow-up, two were lost to follow-up and 19 patients agreed to have a bronchoscopy at 14 years (60\% response rate). Mean \pm SD total follow-up period from baseline was $13.9 \pm 0.5$ years. At baseline and at 14 years of follow-up $\sim 70 \%$ of the patients were using inhaled corticosteroids (table 1). Eight out of 19 patients used long-acting $\beta 2$-agonists at $t=14$ years and none had used them at baseline. During the past 5 years three patients had received one or more courses of oral corticosteroids. At baseline, $\mathrm{PC} 20$ was $<8 \mathrm{mg} \cdot \mathrm{mL}^{-1}$ in all patients, and at $\mathrm{t}=14$ it was below this threshold in 16 out of 19 patients. At baseline, all patients were atopic. However, after 14 years of follow-up, one of the subjects had a negative skin prick test (table 1). At $t=14$ years three patients had become current smokers (table 1). Three patients no longer experienced asthma symptoms at $\mathrm{t}=14$ and therefore did not receive any medication.

\section{Decline in lung function}

There was a significant decline in both pre- and post-bronchodilator FEV1 during the 14 years of follow-up (figure 2 and table 2). Post-bronchodilator FEV 1 showed a significantly larger decline than pre-bronchodilator FEV1 $(\mathrm{p}=0.03)$. Pre-bronchodilator FEV1 showed a mean \pm sD decline of $20.6 \pm 30.0 \mathrm{~mL}$, whereas post-bronchodilator FEV1 declined by $31.0 \pm 22.2 \mathrm{~mL}$. Figure 2 shows the longitudinal progression of pre- and post-bronchodilator FEV1 (figure $2 \mathrm{a}$ and $\mathrm{b}$, respectively) and pre- and post-bronchodilator $\mathrm{FEV}_{1} \%$ predicted (figure $2 \mathrm{c}$ and $\mathrm{d}$, respectively) during the follow-up period of 14 years. Mean FEV $1 \%$ predicted was within the normal range (figure 2 and table 2). Moreover, we analysed the correlation between the decline in $\mathrm{FEV}_{1} \%$ predicted in the first period of follow-up (from baseline to $\mathrm{t}=7.5$ years) and the decline in the second period of follow-up (from $t=7.5$ to $t=14$ years). No significant correlation was observed, suggesting that decline in lung function might be episodic $(\mathrm{p}>0.10)$. 
TABLE 1 Characteristics of asthma patients from the Asthma Management Protocol University Leiden cohort at 14 years of follow-up

\begin{tabular}{|c|c|}
\hline Subjects & 19 \\
\hline Age years & $44.2 \pm 9.4$ \\
\hline Height $\mathrm{cm}$ & $174 \pm 11.1$ \\
\hline Weight kg & $84 \pm 11.5$ \\
\hline \multicolumn{2}{|l|}{ Sex } \\
\hline Males & 11 \\
\hline Females & 8 \\
\hline Mean follow-up years & $13.9 \pm 0.5$ \\
\hline \multicolumn{2}{|l|}{ Inhaled corticosteroid use } \\
\hline Yes n (\%) & $13(68 \%)$ \\
\hline No & 6 \\
\hline \multicolumn{2}{|l|}{ Smoking } \\
\hline Yes & 3 \\
\hline No & 16 \\
\hline \multicolumn{2}{|l|}{ Allergy } \\
\hline Yes & 18 \\
\hline No & 1 \\
\hline Geometric mean $(\mathrm{sD})^{\#} \mathrm{PC}_{20}$ methacholine $\mathrm{mg} \cdot \mathrm{mL}^{-1}$ & $3.44(2.9)$ \\
\hline
\end{tabular}

Data are presented as $\mathrm{n}$ or mean $\pm \mathrm{SD}$, unless otherwise stated. $\mathrm{PC}_{20}$ : provocative concentration causing a $20 \%$ fall in forced expiratory volume in $1 \mathrm{~s} .{ }^{*}$ : Geometric mean (SD in double dose).
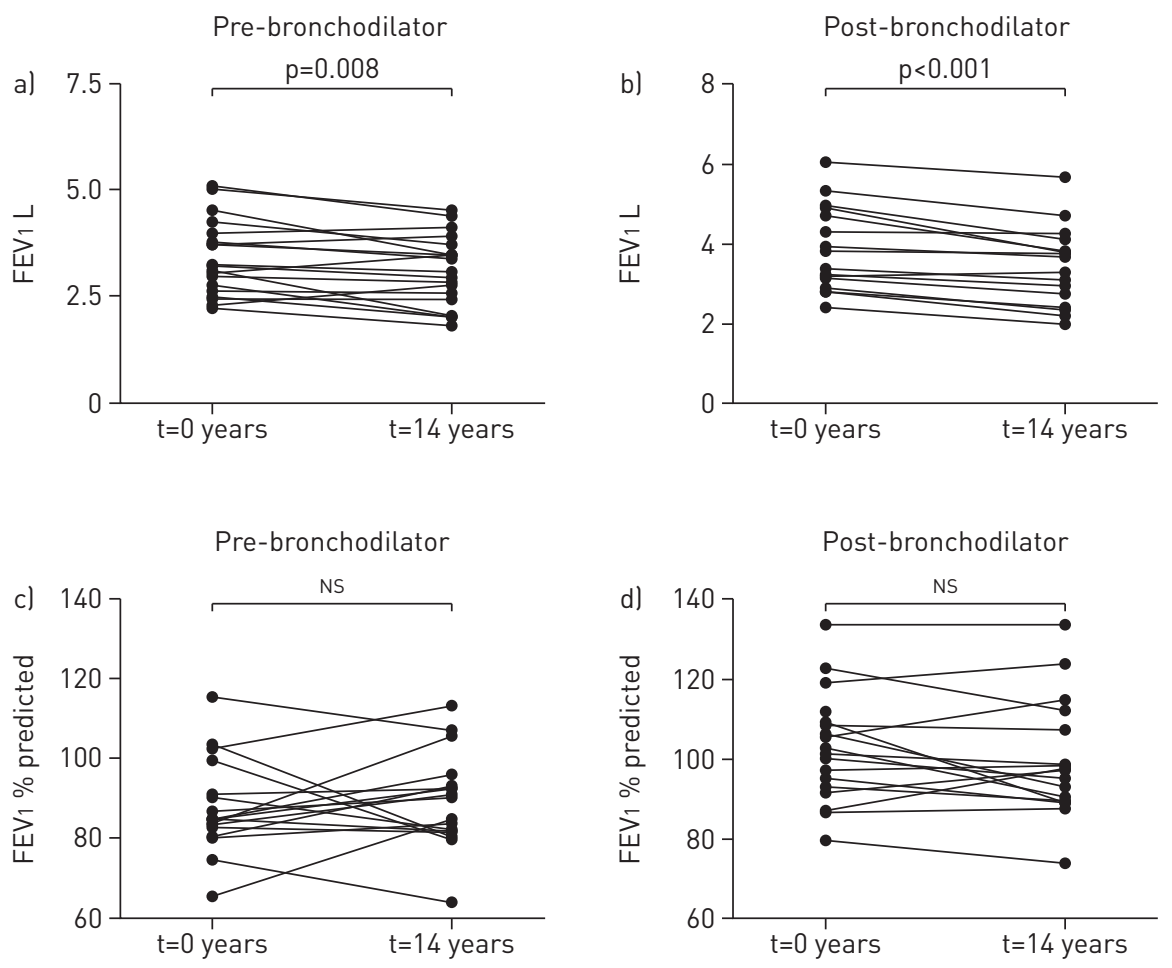

FIGURE 2 Course of a) pre- and b) post-bronchodilator forced expiratory volume in $1 \mathrm{~s}(\mathrm{FEV} 1)$, and c) pre- and d) post-bronchodilator $\mathrm{FEV} 1 \%$ predicted between baseline ( $\mathrm{t}=0$ years) and $\mathrm{t}=14$ years. Ns: nonsignificant.

\section{Longitudinal analysis: prediction of decline in lung function}

Dichotomous analyses showed that asthma patients with higher bronchial CD8 counts at baseline had a significantly larger subsequent decline in pre- and post-bronchodilator $\mathrm{FEV}_{1} \%$ predicted as compared with those with low CD8 counts (figure 3a and b; respectively). Similarly, asthma patients with higher CD4 counts at baseline exhibited a more pronounced decline in pre- and post-bronchodilator FEV $1 \%$ predicted (figure $3 \mathrm{c}$ and $\mathrm{d}$, respectively). These dichotomous analyses were confirmed by nonparametric Spearman's correlation analyses (table 3 ). The other inflammatory and structural markers analysed did not predict subsequent decline in lung function $(\mathrm{p}>0.10)$. 
TABLE 2 Pre- and post-bronchodilator forced expiratory volume in $1 \mathrm{~s}$ (FEV1) of asthma patients from the Asthma Management Protocol University Leiden cohort at baseline and at 14 years at follow-up

\begin{tabular}{|c|c|c|c|}
\hline & Baseline & $t=14$ years & p-value \\
\hline \multicolumn{4}{|l|}{ FEV 1 L } \\
\hline Pre-bronchodilator & $3.38 \pm 0.88$ & $3.09 \pm 0.82$ & $p=0.01$ \\
\hline Post-bronchodilator & $3.86 \pm 1.02$ & $3.46 \pm 0.96$ & $p<0.01$ \\
\hline \multicolumn{4}{|l|}{ FEV $1 \%$ predicted } \\
\hline Pre-bronchodilator & $87.7 \pm 11.3$ & $88.3 \pm 11.5$ & NS \\
\hline Post-bronchodilator & $100.1 \pm 11.1$ & $97.0 \pm 11.5$ & NS \\
\hline
\end{tabular}

Longitudinal analysis: inflammation at the end of follow-up

Asthma patients with higher CD8 counts at $\mathrm{t}=14$ demonstrated a more pronounced decline in both preand post-bronchodilator $\mathrm{FEV}_{1} \%$ predicted during the previous years as compared with those with lower CD8 counts at $\mathrm{t}=14$ (figure $4 \mathrm{a}$ and $\mathrm{b}$, respectively). For granzyme $\mathrm{B}$ and $\mathrm{CD} 3$, decline in pre-bronchodilator FEV1 \% predicted was highest in asthma patients with higher values of these markers at $\mathrm{t}=14$ years. (figure $4 \mathrm{c}$ and $\mathrm{d}$, respectively). These results were confirmed by nonparametric Spearman's analysis (table 3). CD4 and the other markers that were analysed dichotomously displayed no association with a preceding decline in lung function $(p>0.10)$. A significant correlation between CD8 counts at baseline and those at $\mathrm{t}=14$ years was observed $\left(\mathrm{r}_{\mathrm{SP}}=0.52, \mathrm{p}=0.03\right)$, whereas CD3 and CD4 counts at baseline and after follow-up were not correlated $(\mathrm{p}>0.10)$.
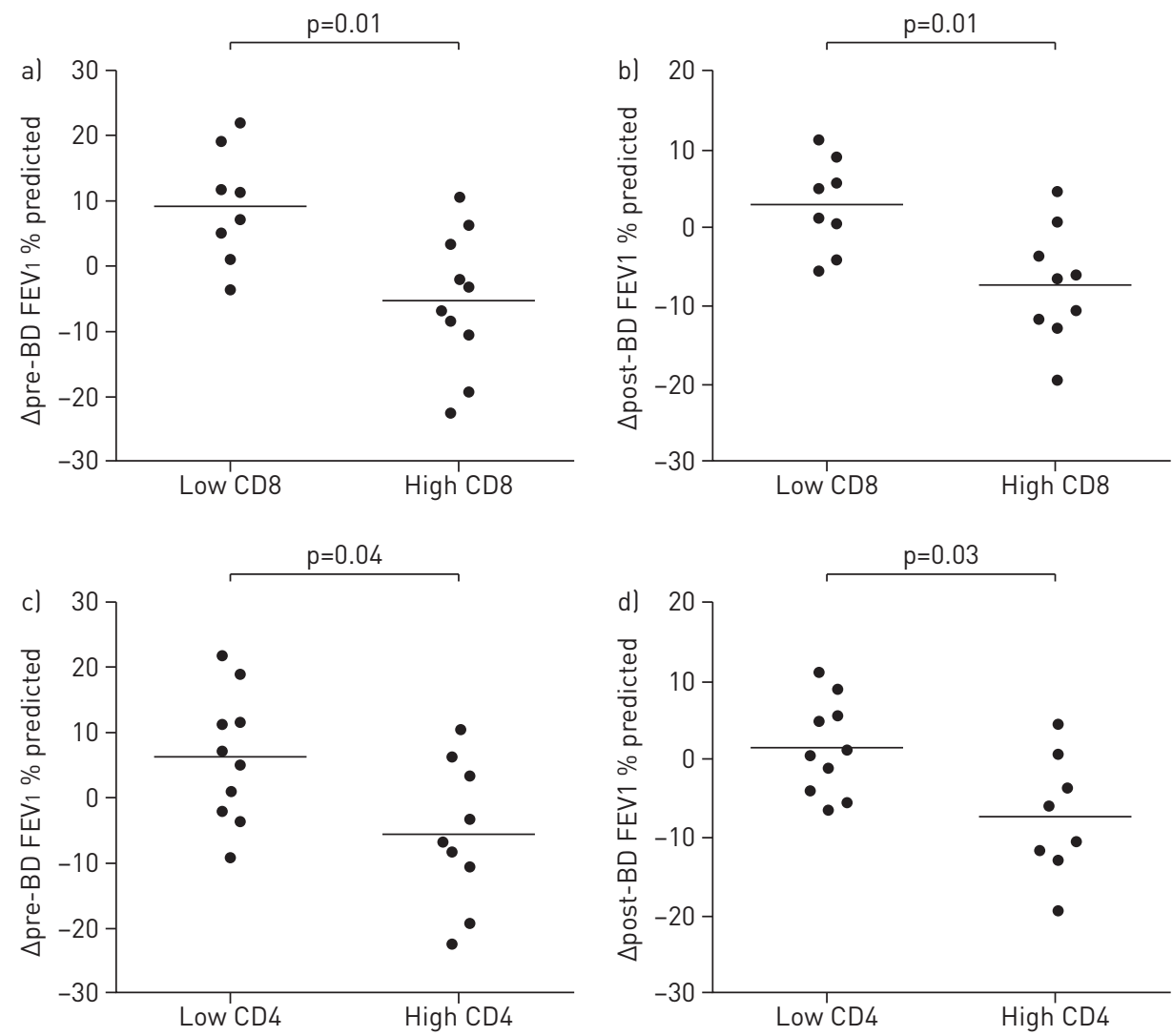

FIGURE 3 Differences in subsequent lung function decline in a) pre- and b) post-bronchodilator (BD) forced expiratory volume in $1 \mathrm{~s}\left(\mathrm{FEV}_{1}\right) \%$ predicted between patients with low and high CD8 counts at baseline. Differences in subsequent lung function decline in c) pre- and d) post-BD FEV $1 \%$ predicted between patients with low and high CD4 counts at baseline. "High" and "low" groups were defined based on medians of the staining ("low" was defined as less than the median and "high" as greater than or equal to the median). Other markers analysed showed no significant differences. Horizontal bars indicate the means. 
TABLE 3 Nonparametric correlation analyses between both staining at baseline $(t=0)$ and subsequent pre- and post-bronchodilator decline in $\mathrm{FEV}_{1} \%$ predicted, and staining at $\mathrm{t}=14$ years and preceding pre- and post-bronchodilator decline in $\mathrm{FEV} 1 \%$ predicted

Decline in $\mathrm{FEV} 1 \%$ predicted $(\mathrm{t}=0-\mathrm{t}=14)$

\begin{tabular}{lcc} 
& Pre-bronchodilator & Post-bronchodilator \\
\hline CD8 $t=0$ & $r_{S P}=-0.49, p=0.04$ & $r_{S P}=-0.57, p=0.02$ \\
CD8 $t=14$ & $r_{S P}=-0.76, p=0.00$ & $r_{S P}=-0.48, p=0.04$ \\
CD4 $t=0$ & $r_{S P}=-0.60, p=0.01$ & $r_{S P}=-0.62, p=0.01$ \\
CD4 $t=14$ & $N S$ & $N S$ \\
CD3 $t=0$ & $N S$ & $N S$ \\
CD3 $t=14$ & $r_{S P}=-0.69, p=0.00$ & $N S$ \\
Granzyme B $t=14$ & $r_{S P}=-0.55, p=0.01$ & $N S$
\end{tabular}

Nonparametric Spearman's rank correlation coefficient $\left(r_{\mathrm{SP}}\right)$ and $\mathrm{p}$-values are given. Analyses of CD8, CD4, $\mathrm{CD} 3$ and granzyme $\mathrm{B}$ are given. The other analyses performed showed no significant associations ( $p>0.10)$. FEV1: forced expiratory volume in $1 \mathrm{~s}$; $r_{\mathrm{SP}}$ : Spearman's correlation coefficient; Ns: nonsignificant.

\section{Cross-sectional analysis}

There was a significant correlation between both CD8 and CD3 counts at $\mathrm{t}=14$ and pre-bronchodilator $\mathrm{FEV}_{1} \%$ predicted at $\mathrm{t}=14$ (figure $5 \mathrm{a}$ and $\mathrm{b}$, respectively), whereas no correlation was found between $\mathrm{CD}^{+}$ cells or the other inflammatory markers, and pre-bronchodilator FEV1 \% predicted at $\mathrm{t}=14(\mathrm{p}>0.10)$.

\section{Discussion}

The present study shows that the number of bronchial $\mathrm{CD}^{+}$- and $\mathrm{CD} 4^{+}$-cells at baseline predicts the subsequent decline in lung function in patients with mild-to-moderate atopic asthma during 14 years of
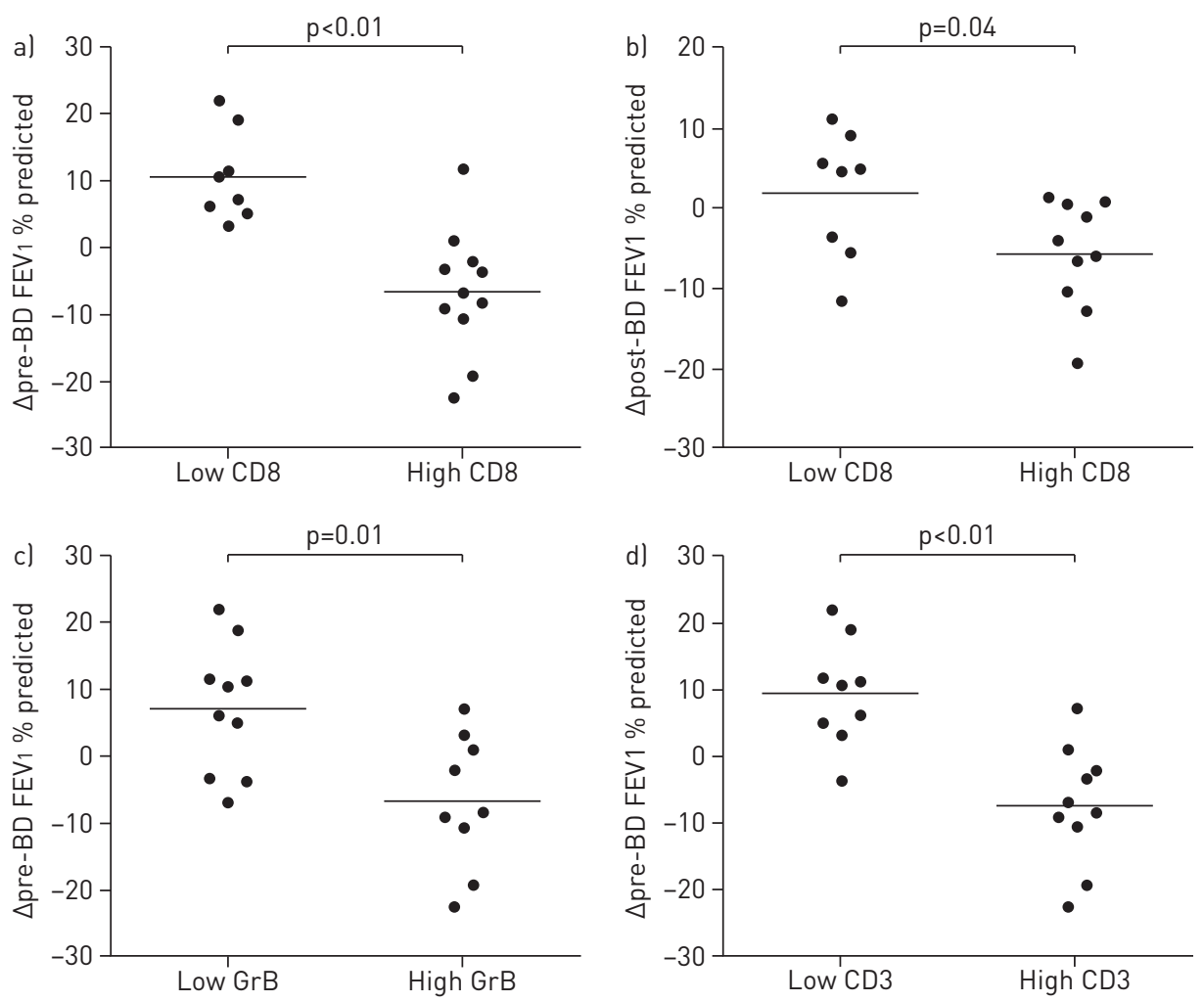

FIGURE 4 Differences between high and low CD8 counts in terms of preceding decline in a) pre-bronchodilator (BD) forced expiratory volume in $1 \mathrm{~s}$ (FEV 1 ) \% predicted and b) post-BD FEV 1 \% predicted. Differences in preceding decline in pre-BD FEV $1 \%$ predicted between c) high and low granzyme B (GrB), and d) between high and low CD3. "High" and "low" groups were defined based on medians of the staining ("low" was defined as less than the median and "high" as greater than or equal to the median). The other analyses performed showed no significant differences. Horizontal bars indicate the means. 
follow-up. At the end of follow-up, the numbers of $\mathrm{CD}^{+}-, \mathrm{CD}^{+}$- and granzyme $\mathrm{B}^{+}$-cells were correlated with the preceding lung function decline. Our data indicate that, despite on average having normal decline, the long-term course of lung function is very heterogeneous among patients with mild-to-moderate asthma, and that subgroups of patients with high CD8 or high CD4 cells in bronchial biopsies might be at risk of more pronounced loss of lung function over many years.

To the best of our knowledge, the present study is the first to examine the relationship between inflammatory markers in bronchial biopsies and the long-term course of lung function in asthma. Previously our group has shown that $\mathrm{CD}^{+}$cells in bronchial biopsies are of prognostic value for subsequent lung function decline in patients with mild-to-moderate asthma during short-term follow-up (7.5 years) [11]. This has now been extended by doubling the follow-up period, and by a follow-up bronchoscopy at $\mathrm{t}=14$ years. Both at baseline and $\mathrm{t}=14$ elevated CD8 counts were associated with a more rapid decline of FEV1, which demonstrates internal validity. Besides CD8 cells, we found that CD4 cells were also predictive for subsequent pre- and post-bronchodilator lung function decline as measured by FEV $1 \%$ predicted. These differences between associations at $t=7.5$ and $t=14$ years might be caused by the fact that we followed these patients over a longer period of time. Our previous study at 7.5 years of follow-up might have missed the association with CD4 cells because the observation period was too short.

What could be the role of CD8 cells in asthma? In patients dying from acute asthma a higher number of activated $\mathrm{CD}^{+} \mathrm{T}$-cells was observed in post-mortem lung tissue samples as compared with tissue from asthmatic and control subjects [12]. However, CD8 cells may also be involved outside acute episodes of asthma, particularly in patients with relatively severe disease. First, activation of circulating $\mathrm{CD}^{+} \mathrm{T}$-cells was recently reported in patients with severe asthma using transcriptome analysis [13]. Secondly, an association between CD8 cells in sputum and asthma severity, as measured by bronchial hyperresponsiveness to histamine, was previously shown by CHо et al. [14]. In addition to production of T-helper (Th) 2 cytokines by $\mathrm{CD}^{+}$T-cells in the asthmatic airways, $\mathrm{CD} 8^{+} \mathrm{T}$-cells were also found to produce interleukin (IL)-4 and IL-5 in the airways in asthma [14, 15]. A recent study suggests an important role for a subset of peripheral blood effector memory IL-6R $\alpha^{\text {high }}$ CD8 cells in the production of Th2 cytokines in asthma [16]. CD8 cells may be triggered by allergens as a result of cross-presentation of exogenous allergen by major histocompatibility complex class I on airway dendritic cells to $\mathrm{CD}^{+}$cells [17]. In mice the response of CD8 cells to aerosolised allergen was found to contribute to pulmonary eosinophilia and bronchial hyperresponsiveness [18]. This notion is supported by studies from SENEviRATNE et al. [19] who defined three CD8 T-cell epitopes for house dust mite allergen.

A link between CD8 cells and asthma might also be explained by respiratory viral infections and other intracellular pathogens, since cytotoxic T-cells play a major role in the defence against such infections. In young children wheezing episodes caused by rhinovirus infections are associated with the development of asthma [20]. Moreover, in more than $80 \%$ of asthma exacerbations viral infections are involved [21, 22], while respiratory viruses have also been observed in the airways in stable patients with asthma [23, 24]. In mice, $\mathrm{CD}^{+} \mathrm{T}$-cells activated in response to viral infections can persist in the airways for several months [25], thereby causing lung damage [26]. This could contribute to airway remodelling leading to a decline in lung function.

Our study shows that $\mathrm{CD}^{+}$-cell counts are relatively constant over time, whereas baseline $\mathrm{CD} 4^{+}-$and $\mathrm{CD}^{+}$-cell counts were not correlated with cell counts at 14 years of follow-up. We postulate that CD8 ${ }^{+}$ cells might contribute to lung function decline as a result of their cytotoxic activity. A recent study in
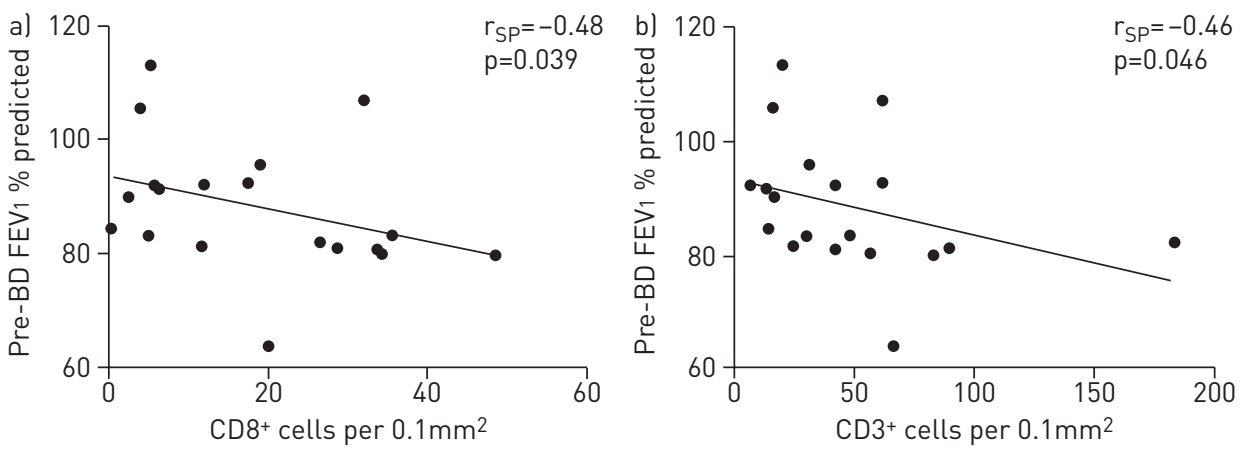

FIGURE 5 Cross-sectional correlation between number of a) $\mathrm{CD}^{+}$and b) $\mathrm{CD}^{+}$cells in lamina propria at $\mathrm{t}=14$ years and pre-bronchodilator (BD) forced expiratory volume in $1 \mathrm{~s}(\mathrm{FEV} 1) \%$ predicted. Spearman's rank correlation coefficients $\left(r_{\mathrm{SP}}\right)$ and $\mathrm{p}$-values are shown. 
chronic obstructive pulmonary disease showed an association between granzyme B expression and small airway remodelling [27]. This is supported by our observation that granzyme B, as a marker of cytotoxic activity, was correlated with the preceding decline in lung function. An additional possibility is that CD8 cells are a major source of IL-13, which is an important cytokine in airway remodelling [28].

Aside from the predictive value of CD8 cells, we also found that CD4 cells were predictive of lung function decline and cross-sectionally related to lung function. However, these cells were not correlated to preceding lung function decline when measured after 14 years of follow-up, and were not constant over time. Since CD4 cells may contribute to activation of naive CD8 cells, this finding may reflect the role of CD4 T-cells in (the early stages of) CD8 T-cell activation. However, it needs to be noted that the correlation was lost when decline in absolute FEV1 was analysed.

CD3 counts were correlated to preceding lung function decline after 14 years of follow-up. No correlation between $\mathrm{CD}^{+}$cells and granzyme B could be found, but granzyme B was correlated with $\mathrm{CD}^{+}$cells (data not shown). This might indicate a role for $\mathrm{CD}^{+} \mathrm{CD}^{+}$natural killer $\mathrm{T}$-cells (iNKT cells), which were found to be increased in bronchoalveolar lavage-fluid from allergic asthmatic patients when compared with healthy controls [29]. Moreover, it was shown that granzyme B was increased in iNKT cells in peripheral blood in allergic asthmatic patients when compared with healthy controls [30]. This suggests that cytotoxic iNKT cells might be involved in the processes that lead to lung function decline in asthma.

The strength of our study is that it describes 14 years of prospective follow-up, using standardised methodologies. Moreover, this study focuses on the heterogeneity in lung function decline and describes subgroups that show a phenotype with a smaller or larger decline in lung function. The heterogeneity in lung function is considerable and might be affected by many factors. Therefore, we considered the possibility that the associations between inflammatory markers and lung function decline were explained by differences in medication use. However, the results of our regression analysis were not affected by the use of inhaled corticosteroids as demonstrated when including corticosteroid use as a covariate (table S2). Nevertheless, there are several potential limitations. First, this study was performed in a relatively small cohort, as several patients were lost to follow-up after 14 years or were no longer willing to participate. However, it is unlikely that this has markedly affected our conclusions since: 1) the sample size was adequate for repeated measures of bronchial biopsy cell counts; 2) no differences were observed in lung function and corticosteroid use between patients who participated in the follow-up study and those who did not $(p>0.10)$; and 3 ) we did find correlations between long-term lung function decline and inflammatory markers in the airways. Secondly, in view of developments in immunohistochemistry and data on predominant inflammatory pathways in asthma since the early 1990s, the methods of staining at $t=0$ and $t=14$ years were not identical. Thirdly, during the follow-up period patients were receiving asthma treatment from their own general practitioner, and for some patients, a chest physician. After 14 years, three of the 19 patients were not suffering from any asthma symptoms at all and were not receiving any asthma medication, while two-thirds of the patients were receiving inhaled corticosteroids. Fourthly, while CD8 counts at baseline were correlated with CD8 counts after 14 years of follow-up, it cannot be concluded that the elevated CD8 counts at baseline and the elevated CD8 counts at the end of the study are a reflection of a continuous process and/or are the results of similar triggers. Finally, at baseline none of the patients were current smokers. However, after 14 years of follow-up, three of the 19 patients had become current smokers (16\%), of which two patients had smoked 2 pack-years and one patient had smoked 5 pack-years. Because of the limited prevalence of smoking in this cohort, we cannot draw conclusions on the influence of smoking on the parameters and associations studied. However, it is relevant to note that the results of our regression analysis were not affected by smoking (despite its low prevalence) as shown when using smoking as a covariate in the analysis (table S2).

Despite the substantial variability of lung function decline in our cohort, the average lung function decline in this group of patients with mild-to-moderate asthma was still within normal limits. LANGE et al. [1] found declines of $38 \mathrm{~mL}$ per year in self-reported asthma and $22 \mathrm{~mL}$ per year in healthy subjects, with large variability. In our study, pre- and post-bronchodilator FEV1 declined by 21 and $31 \mathrm{~mL}$ per year, respectively. The decline we found is less pronounced, however, the decline in post-bronchodilator FEV 1 was substantial when compared with the decline in healthy individuals. An explanation for the limited lung function decline might be that the patients in our cohort suffer from relatively mild disease. Nevertheless, given the results of $\mathrm{CHO}$ et al. [14] and Tsirsiou et al. [13] and our observation that more pronounced lung function decline is associated with more airway inflammation it cannot be excluded that our observations are also of relevance for more severe cases of asthma.

Identification and characterisation of phenotypic subgroups of asthma is relevant in relation to the clinical course of the disease [2] and responses to treatment [7]. Even though clusters of patients based on clinical, cellular and gene expression data have been identified in mild-to-moderate asthma [31-33], such clusters 
have not yet been linked to long-term disease outcome. Therefore, phenotyping is likely to contribute to the development of targeted therapies, which could have benefits for the treatment of both acute and long-term asthma symptoms.

\section{Acknowledgements}

First, the authors thank the patients of the Asthma Management Protocol University Leiden (AMPUL) study cohort for their participation. Moreover, the authors thank J. Gast-Strookman, R.G.M. van Steijn, W. Thijs and J. de Kluijver (Dept of Pulmonology, Leiden University Medical Center, Leiden, the Netherlands) for their help with the patient visits and E.L.J. van Rensen (Dept of Pulmonology, Leiden University Medical Center, Leiden, the Netherlands) for the discussions about the AMPUL study cohort.

\section{References}

1 Lange P, Parner J, Vestbo J, et al. A 15-year follow-up study of ventilatory function in adults with asthma. $N$ Engl J Med 1998; 339: 1194-1200.

2 Grol MH, Gerritsen J, Vonk JM, et al. Risk factors for growth and decline of lung function in asthmatic individuals up to age 42 years. A 30-year follow-up study. Am J Respir Crit Care Med 1999; 160: 1830-1837.

3 Peat JK, Woolcock AJ, Cullen K. Rate of decline of lung function in subjects with asthma. Eur J Respir Dis 1987; 70: $171-179$

4 Vignola AM, Kips J, Bousquet J. Tissue remodeling as a feature of persistent asthma. J Allergy Clin Immunol 2000; 105: 1041-1053.

5 ten Brinke A, Zwinderman AH, Sterk PJ, et al. Factors associated with persistent airflow limitation in severe asthma. Am J Respir Crit Care Med 2001; 164: 744-748.

6 Lange P, Ulrik CS, Vestbo J. Mortality in adults with self-reported asthma. Copenhagen City Heart Study Group. Lancet 1996; 347: 1285-1289.

7 Szefler SJ, Martin RJ, King TS, et al. Significant variability in response to inhaled corticosteroids for persistent asthma. J Allergy Clin Immunol 2002; 109: 410-418.

8 Green RH, Brightling CE, Woltmann G, et al. Analysis of induced sputum in adults with asthma: identification of subgroup with isolated sputum neutrophilia and poor response to inhaled corticosteroids. Thorax 2002; 57: 875-879.

9 Nair P, Pizzichini MM, Kjarsgaard M, et al. Mepolizumab for prednisone-dependent asthma with sputum eosinophilia. N Engl J Med 2009; 360: 985-993.

10 Sont JK, Willems LN, Bel EH, et al. Clinical control and histopathologic outcome of asthma when using airway hyperresponsiveness as an additional guide to long-term treatment. The AMPUL Study Group. Am J Respir Crit Care Med 1999; 159: 1043-1051.

11 van Rensen EL, Sont JK, Evertse CE, et al. Bronchial CD8 cell infiltrate and lung function decline in asthma. Am J Respir Crit Care Med 2005; 172: 837-841.

12 O'Sullivan S, Cormican L, Faul JL, et al. Activated, cytotoxic $\mathrm{CD}^{+} \mathrm{T}$ lymphocytes contribute to the pathology of asthma death. Am J Respir Crit Care Med 2001; 164: 560-564.

13 Tsitsiou E, Williams AE, Moschos SA, et al. Transcriptome analysis shows activation of circulating CD8 ${ }^{+} \mathrm{T}$ cells in patients with severe asthma. J Allergy Clin Immunol 2012; 129: 95-103.

14 Cho SH, Stanciu LA, Holgate ST, et al. Increased interleukin-4, interleukin-5, and interferon-gamma in airway $\mathrm{CD}^{+}$and $\mathrm{CD}^{+} \mathrm{T}^{-}$cells in atopic asthma. Am J Respir Crit Care Med 2005; 171: 224-230.

15 Ying S, Humbert M, Barkans J, et al. Expression of IL-4 and IL-5 mRNA and protein product by CD4 $4^{+}$and CD8 ${ }^{+}$ $\mathrm{T}$ cells, eosinophils, and mast cells in bronchial biopsies obtained from atopic and nonatopic (intrinsic) asthmatics. J Immunol 1997; 158: 3539-3544.

16 Lee N, You S, Shin MS, et al. IL-6 receptor $\alpha$ defines effector memory CD8 ${ }^{+} \mathrm{T}$ cells producing Th2 cytokines and expanding in asthma. Am J Respir Crit Care Med 2014; 190: 1383-1394.

17 Wells JW, Cowled CJ, Giorgini A, et al. Regulation of allergic airway inflammation by class I-restricted allergen presentation and CD8 T-cell infiltration. J Allergy Clin Immunol 2007; 119: 226-234.

18 Sawicka E, Noble A, Walker C, et al. Tc2 cells respond to soluble antigen in the respiratory tract and induce lung eosinophilia and bronchial hyperresponsiveness. Eur J Immunol 2004; 34: 2599-2608.

19 Seneviratne SL, Jones L, King AS, et al. Allergen-specific $\mathrm{CD}^{+} \mathrm{T}$ cells and atopic disease. J Clin Invest 2002; 110: 1283-1291.

20 Jackson DJ, Gangnon RE, Evans MD, et al. Wheezing rhinovirus illnesses in early life predict asthma development in high-risk children. Am J Respir Crit Care Med 2008; 178: 667-672.

21 Johnston SL, Pattemore PK, Sanderson G, et al. Community study of role of viral infections in exacerbations of asthma in 9-11 year old children. BMJ 1995; 310: 1225-1229.

22 Nicholson KG, Kent J, Ireland DC. Respiratory viruses and exacerbations of asthma in adults. BMJ 1993; 307: 982-986.

23 Wos M, Sanak M, Soja J, et al. The presence of rhinovirus in lower airways of patients with bronchial asthma. Am J Respir Crit Care Med 2008; 177: 1082-1089.

24 Turchiarelli V, Schinkel J, Molenkamp R, et al. Repeated virus identification in the airways of patients with mild and severe asthma during prospective follow-up. Allergy 2011; 66: 1099-1106.

25 Hogan RJ, Usherwood EJ, Zhong W, et al. Activated antigen-specific CD8 ${ }^{+} \mathrm{T}$ cells persist in the lungs following recovery from respiratory virus infections. J Immunol 2001; 166: 1813-1822.

26 Cannon MJ, Openshaw PJ, Askonas BA. Cytotoxic T cells clear virus but augment lung pathology in mice infected with respiratory syncytial virus. J Exp Med 1988; 168: 1163-1168.

27 Kim WD, Chi HS, Choe KH, et al. A possible role for $\mathrm{CD} 8^{+}$and non-CD8 ${ }^{+}$cell granzyme B in early small airway wall remodelling in centrilobular emphysema. Respirology 2013; 18: 688-696.

28 Dakhama A, Collins ML, Ohnishi H, et al. IL-13-producing BLT1-positive CD8 cells are increased in asthma and are associated with airway obstruction. Allergy 2013; 68: 666-673.

29 Akbari O, Faul JL, Hoyte EG, et al. $\mathrm{CD}^{+}{ }^{+}$invariant T-cell-receptor ${ }^{+}$natural killer $\mathrm{T}$ cells in bronchial asthma. N Engl J Med 2006; 354: 1117-1129. 
30 Nguyen KD, Vanichsarn C, Nadeau KC. Increased cytotoxicity of $\mathrm{CD} 4^{+}$invariant NKT cells against CD4+ CD25hiCD127lo/-regulatory T cells in allergic asthma. Eur J Immunol 2008; 38: 2034-2045.

31 Haldar P, Pavord ID, Shaw DE, et al. Cluster analysis and clinical asthma phenotypes. Am J Respir Crit Care Med 2008; 178: 218-224.

32 Simpson JL, Scott R, Boyle MJ, et al. Inflammatory subtypes in asthma: assessment and identification using induced sputum. Respirology 2006; 11: 54-61.

33 Baines KJ, Simpson JL, Wood LG, et al. Transcriptional phenotypes of asthma defined by gene expression profiling of induced sputum samples. J Allergy Clin Immunol 2011; 127: 153-160. 